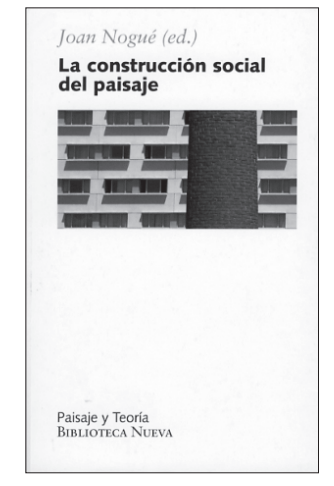

\section{Joan Nogué (editor). La construcción social del paisaje}

\author{
Madrid: Biblioteca Nueva, 2007, 343 p.
}

\author{
Perla Zusman ${ }^{1}$
}

A partir de la firma de la Convención Europea del paisaje, en Florencia el año 2000, la discusión sobre este tema adquiere un espacio destacado en los ámbitos políticos y académicos de España. En el año 2004, en la ciudad de Olot, Cataluña, se organizó el Observatorio del Paisaje con el fin de convertirse en un espacio de reflexión y acción sobre el paisaje. El Observatorio fue también pensado como un ámbito de negociación entre la Generalitat de Catalunya, las administraciones locales, las universidades, los colectivos profesionales y el conjunto de la sociedad en todo lo relacionado con la gestión y conservación del paisaje (Observatori del Paisatge, 2009).

Una de las primeras actividades que emprendió Joan Nogué como director del Observatorio fue la organización de tres seminarios consecutivos sobre la temática; el primero denominado Las estéticas del paisaje (2003), el segundo, Los paisajes de la modernidad (2004) y, el tercero, Paisajes incógnitos, territorios ocultos: las geografías de la invisibilidad (2005). Estos encuentros tuvieron en común el interés por traer a la discusión las visiones más actuales sobre el paisaje, construidas desde distintos saberes (las ciencias sociales, las artes, la arquitectura, entre otros), en distintos países (fundamentalmente europeos y americanos).

Los trabajos de estos seminarios han sido recopilados en dos libros coordinados

\footnotetext{
1 Universidad de Buenos Aires (Argentina). E-mail: perlazusman@yahoo.es
}

por Joan Nogué: La construcción social del paisaje (2007) y El paisaje en la cultura contemporánea $(2008)^{2}$. Tanto la coordinación del Observatorio como la organización de los seminarios y edición de los libros reflejan el interés del propio Joan Nogué por articular lo político y lo académico, la discusión teórica y la intervención territorial, a través de una temática que despierta su interés desde su tesis doctoral sobre el paisaje de la Garrotxa (comarca catalana donde se sitúa la ciudad de Olot), realizada en la Universidad de Madison bajo la dirección de Yi Fu Tuan. Este trabajo, orientado por la perspectiva humanista, recuperó las experiencias vividas (reflejadas también en la producción artística) que han contribuido a la construcción de la identidad de esta comarca pirenaica. De esta manera, Joan Nogué buscaba incorporase en las discusiones que autores como Edward Relph, Yi Fu Tuan o Eugenio Turri venían realizando sobre la estandarización y homogeneización de paisajes y sobre sus implicaciones en la pérdida de la identificación de las comunidades locales con los

\footnotetext{
2 Los libros forman parte de una colección sobre paisaje editada por la Biblioteca Nueva de Madrid. Esta colección, coordinada por Federico López Silvestre, Javier Maderuello y Joan Nogué, traduce y publica distintos trabajos producidos en teoría e historia del paisaje en los últimos años. El texto que se reseña es el primero de la colección. Dentro de esta serie sobre paisaje y teoría, hasta el momento se han publicado los siguientes libros: Breve tratado del paisaje (Roger, 2007), El arte del paisaje (Berque, 2007), El pensamiento paisajero (Berque, 2009) y Miradas sobre el paisaje (Martínez de Pisón, 2009).
} 
lugares. Esta preocupación se hace también presente en el proyecto que orienta el trabajo del Observatorio del Paisaje: a través de una metodología participativa se persigue recuperar la historia y geografía de los lugares presentes en los paisajes.

\section{Las implicancias de construir socialmente el paisaje}

Simultáneamente a esta preocupación de la sociedad actual de corte histórico y ambiental se observa un interés por multiplicar las perspectivas de abordaje del paisaje. Así, por ejemplo, a las orientaciones clásicas de la geografía por estudiar las formas visibles delineadas por Otto Schlüter en Alemania y Carl Sauer en Estados Unidos hacia la década de 1920, se le han agregado otras perspectivas, que tienen una raigambre en las propuestas de David Lowenthal, de otorgar mayor importancia a las actitudes de los sujetos en relación a los paisajes o de comprender la producción de representaciones sobre este en tanto expresión de las relaciones sociales y económicas en una formación social como lo proponía en la década de 1980 Denis Cosgrove. Más recientemente, las propuestas fenomenológicas contribuyeron a comprenderlos como resultados de experiencias cotidianas de los sujetos, por lo tanto en constante proceso de producción (open-ended) y como vehículo de conflictos sociales.

Algunas de estas perspectivas orientan los abordajes de "La construcción social del paisaje". Así, los paisajes son construidos desde posturas articuladas en el marxismo (en Muerte en la abundancia: Ios paisajes como sistemas de reproducción social de Don Mitchell), en la fenomenología (en La construcción social de los paisajes invisibles y del miedo de Alicia Lindón y Paisajes fugaces y geografías efímeras en las metrópolis contemporáneas de Daniel Hiernaux) o en el posestructuralismo (en El paisaje como metáfora visual: cultura e identidad en la nación posmoderna de Mireia Folch Serra y Cuerpo y palabra o los paisajes de la cautividad de Josepa Bru), en la percepción (en Paisajes del Cuerpo de María Ángeles Durán), en los recuerdos y olvidos (de la migración gallega, propios de las pinturas Caste- lao o del fotógrafo Virgilio Vietez rastreados en el texto Paisajes del recuerdo y del olvido de Carmen Pena) o en la interrelación entre estructuras, formas y sus manifestaciones visibles (en Paisaje cultura y territorio de Martínez de Pisón). Más allá de estas diferentes propuestas que orientan la forma de elaborar y operativizar el concepto en cuestión, parece existir en todo el libro cierto consenso sobre el hecho que el paisaje es una producción eminentemente cultural, lo que supone también cierta visión sobre las ideas, concepciones y significados de la naturaleza asociadas a cada grupo social.

Las múltiples perspectivas Ilevan a la proliferación de paisajes de los cuales "La construcción social del paisaje" también se hace portavoz. Así, el texto reconoce distintos tipos de paisajes producidos en diversos contextos espacio-temporales: desde los paisajes inventados y manipulados en el contexto del conflicto palestino-israelí (Mireia Folch Serra) o en la desigualdad económica interfronteriza entre México y Estados Unidos (los paisajes como sistema de reproducción social de Don Mitchell), hasta aquellos construidos por la formalidad e informalidad urbanística en Río de Janeiro (Los paisajes de la ciudad oculta de Raquel Tardin) o en las barriadas populares de México (Alicia Lindón), pasando por aquellos homogéneos elaborados en las metrópolis europeas (La ciudad, paisaje invisible de Oriol Nel.lo; Paisajes urbanos con-texto y sin-texto de Xerardo Estévez y Paisajes aterritoriales, paisajes en huelga de Francesc Muñoz).

A continuación se desea explorar tres discusiones que están presentes en algunos capítulos del libro y que se consideran como tres contribuciones al debate del paisaje en el marco de la geografía.

La primera discusión tiene que ver con la preeminencia de la visión en la construcción de los paisajes. La vista ha sido concebida por mucho tiempo como el principal sentido desde el cual se construye conocimiento en la cultura racional occidental. Bajo los influjos del empirismo ingenuo se consideró que era posible conocer la realidad tal cual es a través de la observación. Esta concepción ha dejado una fuerte huella en las formas de aproximarse a la idea pai- 
saje. De hecho, varios autores otorgan importancia a la contemplación y a la mirada en su configuración, aunque, en muchos de los casos, se comprende que la mirada es una producción cultural asociada a otras instancias cognitivas, lo que implica que el proceso de conocimiento no acaba en la visualización. "La construcción social del paisaje" aborda las implicaciones sociales de los actos de ver ${ }^{3}$. Así, seis de los trece textos que conforman el libro discuten la relación entre los paisajes visibles y los no visibles. Algunos de los trabajos siguen el tratamiento entre lo visible y lo invisible planteado por John K. Wright: lo que es invisible para algunos es invisible para otros. En este sentido, existen paisajes que los académicos no ven, por lo tanto no tematizan pero, más aún, los propios habitantes no reconocen los paisajes habitados por otros (sectores populares, ricos o migrantes) y que forman parte de la vida cotidiana de muchas personas: los paisajes del miedo (localizados en las zonas periféricas de la ciudad, asociados a áreas baldías, ámbitos oscuros a recorrer o amplias extensión a recorrer), los paisajes de la ciudad oculta (cortiços y favelas) o los paisajes efímeros y fugaces (conformados a partir de la movilidad que exige la compresión espacio-temporal actual o por las nuevas formas de consumo). Oriol Nel.lo destaca que la invisibilidad (provocada por la propia forma de expansión de la ciudad, por la fragmentación y la inseguridad que desanima a conocer el espacio de los otros) pone en cuestión la propia naturaleza de la ciudad como espacio de encuentro y convivencia. Otra perspectiva de la invisibilidad es planteada por Itziar González Virós en su trabajo "La percepción y el trazado del territorio latente". En este artículo, paisajes latentes -materiales y simbólicos- pueden identificarse en la ciudad: mientras que los

\footnotetext{
3 José Luis Brea (2005) entiende por actos de ver "no solo el más activo de mirar y cobrar conocimiento y adquisición cognitiva de lo visionado (...) sino todo el amplio repertorio de modos de hacer relacionados con el ver y el ser visto, el mirar y el ser mirado, el vigilar y el ser vigilado, el producir las imágenes y diseminarlas o el contemplarlas y percibirlas..., y la articulación de relaciones de poder, dominación y privilegio, sometimiento, control... que todo ello conlleva" (Brea, 2005: 9).
}

materiales se vinculan a los cursos de aguas subterráneas que definen la configuración urbana de algunas ciudades europeas, los simbólicos se asocian a la memoria de los pobladores, que es necesario sacar a la luz para reconstruir paisajes pasados. En muchos de los capítulos se sugiere que la planificación urbana o la participación ciudadana podría contribuir a hacer visible lo invisible, pero también podría pensarse que los propios procesos de visibilidad generarán otras invisibilidades.

La segunda discusión que se desea explorar es la ruptura de una relación directa entre paisaje y escala, generalmente regional, destacada por sobre todo en el planteamiento de la geografía vidaliana francesa. A lo largo del libro puede observarse la elaboración de paisajes a nivel nacional (Folch Serra), regional (Mitchell y Pena), local (Lindón) o individual (Durán y Bru), y estos paisajes participan también en la construcción de dichas escalas. Una muestra clara de este quiebre de la relación directa entre paisaje y escala regional la ofrecen los textos de María Ángeles Durán, "Paisajes del cuerpo", y de Josepa Bru, "Cuerpo y palabra o los paisajes de la cautividad", al explorar el papel del cuerpo en la definición de paisajes que definen la propia personalidad. Estas propuestas articuladas desde el feminismo demuestran el papel activo de la experiencia sexuada en la elaboración de los paisajes que definen de la forma de estar en el mundo. En esta experiencia no solo la vista y su correlato, el discurso logocéntrico, participan, sino también el instinto dionisíaco nietzschiano y otros sentidos como el olfato, el tacto o los sonidos ${ }^{4}$ son puestos en juego a la hora de explorar la relación entre cuerpo y entorno, de liberar al primero de la cautividad al que suele encerrarlo la aproximación euclidiana y desfigurada (sin sujeto o de reconocerse un sujeto es masculino), al ambiente. ¿Faltaría trabajar la relación entre paisajes y multiescalaridad? Se trata de un tipo de análisis que trasciende el propio tex-

\footnotetext{
4 Algunos estudios recientes destacan la construcción de paisajes desde otros sentidos diferentes del de la vista; los estudios feministas han hecho algunas contribuciones en esta línea de tematizar también los paisajes olfativos, sonoros y táctiles.
} 
to, pero que sería sugerente profundizar dentro de la disciplina a la luz de ciertos procesos que se observan en la actualidad ${ }^{5}$.

Finalmente, la última discusión que se quiere destacar es aquella presente en los textos escritos por Xerardo Estévez, "Paisajes urbanos con-texto y sin-texto" y "Paisajes aterritoriales, paisajes en huelga" de Francesc Muñoz. Se concibe que la producción de formas estandarizadas (asociadas al consumo, al negocio y a la especulación; más relacionadas con una imagen que con la historia de un territorio) tiene preeminencia en el mundo de hoy. Estos paisajes definidos por Francesc Muñoz como en huelga y por Xerardo Estévez como sin-texto, parecerían interactuar poco con aquellos producidos en la vida cotidiana de las personas. Se podría plantear si las propias formas estandarizadas no son recreadas en los lugares, dotadas de nuevos significados. En más de veinte años aquellas formas asociadas a los no lugares de Marc Augé se tornaron en contenedores plenos de sentidos para distintos actores sociales. Por ejemplo, los centros comerciales en las grandes ciudades de Argentina se tornaron espacios de encuentro y de conflicto de las tribus urbanas. Se piensa en la resignificación de los aeropuertos internacionales a la luz de haberse tornado en fronteras de los Estados europeos, en tanto espacio en que se dirime el ingreso o deportación de inmigrantes. En la misma línea de pensamiento se podría emprender el camino de rastrear pintores, artistas y escritores que están otorgándole una carga cultural a estos paisajes actuales. Esto no significa obviar los procesos especulativos o de elitización desencadenados por el establecimiento de estas nuevas formas. Sin embargo, en este sentido, también se podría pensar si algunas de las estrategias de protección de paisajes, como aquellas ofrecidas por la UNESCO, no están conformando también paisajes en huelga y sin-texto en la medida que, en algunos casos, responden a intereses y requerimientos ajenos a los de los pobladores lo-

\footnotetext{
5 De hecho, tanto la Convención Europea del Paisaje como el reconocimiento de paisajes culturales como Patrimonio de la Humanidad son normas globales que interactúan con otras locales en las prácticas de preservación.
}

cales, y es el turismo que está orientando algunos procesos de patrimonialización. Ello lleva a deducir que el problema de protección de paisajes con texto y con historia no se resuelve necesariamente con la puesta en práctica de estrategias de protección, sino que requiere fundamentalmente la reformulación del modelo económico.

Ahora bien, en medio de esta discusión, cabe preguntarse cuáles son los paisajes que pueden considerarse como las marcas del siglo XX a XXI. Alain Roger reconoce cierta incapacidad de la sociedad actual, cierta esclerosis de la mirada, para identificar los paisajes que ella produce y que conduce a ir en una búsqueda por un pasado romántico o por una naturaleza presentada como prístina. "Todavía no sabemos ver nuestros complejos industriales, nuestras ciudades futuristas, el poder paisajístico de una autopista" (Roger, 2009: 121-122). Entonces, cuáles serán los paisajes que las sociedades futuras reconocerán como nuestros; seguramente ellas se depararán con algunos de los paisajes descritos en "La construcción social del paisaje": algunos de los estandarizados, algunos de los visibles y algunos de los invisibles (quizás ellos tengan la capacidad de identificar aquellos otros paisajes que esta cultura no deja ver, a los que se refiere $A$. Roger) y algunos de los recuperados/inventados (entendiendo que la producción de ellos se asoció a una fuerte nostalgia por el pasado).

De lo dicho hasta aquí se puede inferir que, en primer lugar, "La construcción social del paisaje" ofrece elementos para comprender las formas en que las ciencias sociales hoy discuten la idea de paisaje, las que dialogan con aquellas que se desarrollan en la geografía; en segundo lugar, ayuda a identificar los paisajes que se reconocen hoy; y en tercero, permite seguir las preocupaciones de época que se tejen en torno a este concepto y a sus referentes empíricos.

\section{Referencias bibliográficas}

BERQUE, A. El pensamiento paisajero. Madrid: Biblioteca Nueva, 2009.

BREA, J. L. Los estudios visuales: por una epistemología política de la visualidad. En: 
BREA, J. L. (ed.). Estudios visuales de la visualidad en la era de la GLOBALIZACIÓN. Madrid: Ed. Akal, 2005, p. 5-14.

MARTÍNEZ DE PISÓN, E. Miradas sobre el paisaje. Madrid: Biblioteca Nueva, 2009.

MILANI, R. El arte del paisaje. Madrid: Biblioteca Nueva, 2007.
OBSERVATORI DEL PAISATGE. Presentación. Olot: Observatori del Paisetge, 2009. Disponible en Internet: http:// www.catpaisatge.net/esp/observatori.php

ROGER, A. Breve tratado del paisaje. Madrid: Biblioteca Nueva, 2009. 